\title{
Considerações exploratórias sobre a atualidade da temática do Planejamento Público: uma homenagem ao economista Celso Furtado
}

\author{
Exploratory considerations on the current issue of Public Planning: \\ a tribute to economist Celso Furtado
}

\section{Bruno Sobral}

Doutor em Desenvolvimento Econômico pelo IE/UNICAMP Professor da Faculdade de Ciências Econômicas - FCE/UERJ Coordenador da Rede Pró-Rio Diretor de Planejamento e Orçamento - DIPLAN/UERJ para a gestão 2020-2023 brunoleo.rj@hotmail.com

\begin{abstract}
Resumo $O$ artigo busca fazer um diálogo aberto conceitualmente com a obra de Celso Furtado e trazê-la para um exercício reflexivo independente sobre uma temática que lhe foi cara: o planejamento público. Considerando este como o exercício de elaboração e execução de planos de modernização que se reconheça a condição histórica de trajetória e garanta uma unidade de ação baseada numa dimensão participativa, alguns aspectos do planejamento serão abordados. Espera-se assim enfatizar a relação do planejamento com um grande desafio de compartilhar socialmente responsabilidades sobre a prática de gestão pública orientada para resultados, no qual o planejamento se revela o instrumento técnico-político de transformação.
\end{abstract}

Palavras Chaves: Celso Furtado; Planejamento; Modernização.

\begin{abstract}
The article wants an open dialogue conceptually with the work of Celso Furtado and brings it to an independent reflective exercise on a theme that was dear to him: public planning. Consider this as the exercise of elaboration and executing modernization plans that recognize the historical condition of trajectory and guarantee a unit of action based on participatory, some aspects of planning will be discussed. Thus, it is hoped to emphasize the relationship between planning and a big challenge of socially sharing responsibilities on the practice of public management oriented towards results, in which planning proves to be the technicalpolitical instrument of transformation.
\end{abstract}

Keywords: Celso Furtado; Planning; Modernization. 
“A velha classe política emergiu com os seus cacoetes, e a opinião pública tende a afastar-se, predominando o cinismo e o ceticismo. (...) o centro da cena está ocupado por (...) tecnocratas travestidos de estadistas e aventureiros disfarçados em tecnocratas. Engana-se o povo da maneira mais descarada". (FURTADO, 2019: 265)

Celso Furtado possui inúmeras contribuições ao pensamento social brasileiro. Sendo sua visão discutida por tantos campos das ciências sociais é esperado que cada um avalie a obra do autor sobre seu viés interpretativo. A proposta do presente texto se situa nos aspectos da obra do mestre como um economista que, convertido ao papel de policy maker, possui a capacidade de dialogar com o público em geral e não apenas com seus pares. Nesse sentido, valorizá-lo enquanto economista crítico dotado de grande preocupação com a relação da economia com a política diante de sua experiência como gestor público.

Todavia, o presente trabalho não busca fazer uma resenha dos conceitos fundamentais em sua obra nem tem a pretensão de reproduzir o debate já consolidado sobre o sentido geral do pensamento do mestre. Como um trabalho em sua homenagem, opta-se por um exercício de livre pensar, ou seja, um diálogo aberto conceitualmente com sua obra e trazê-la para um exercício reflexivo independente sobre uma temática que lhe foi cara: a temática do planejamento público.

Desde já é importante explicitar a definição de planejamento público que será utilizada ao longo do artigo. Trata-se do exercício de elaboração e execução de planos de modernização em que se reconheça a condição histórica de trajetória e garanta uma unidade de ação baseada numa dimensão participativa. Para isso, aspectos do planejamento devem ser relacionados de modo a se tornarem uma alternativa a prática de impor um paradigma único (logo, ahistórico) que tende a uma modernidade deformada propositadamente, em particular, por ser funcional ao processo de assimilação assimétrica e espoliativa da periferia de origem colonial ao sistema capitalista. Da mesma forma, eles devem ser relacionados para não equivaler a uma modernização conservadora que se confunda ao uso abusivo e arbitrário da força e das organizações administrativas junto a uma doutrina tecnocrática a serviço da segurança e controle das classes dominantes.

Especificamente, o presente artigo tratará de três aspectos do planejamento nas próximas seções: 1) um ofício de estadistas elevando a racionalidade pública a um grau 
superior, 2) uma capacidade de ampliar o campo da decisão política, 3) um exercício discricionário para definir prioridades e temporalidades estratégicas.

Ao fazer algumas considerações exploratórias baseando-se nesses aspectos, espera-se reafirmar como o planejamento pode ser encarado como um processo organizado de despertar de uma consciência coletiva sobre o diagnóstico de um conjunto de problemas fundamentais, a definição de diretrizes e metas de realização, a tarefa de mobilização dos atores sociais etc. Nesse sentido, trata-se de um grande desafio de compartilhar socialmente responsabilidades sobre a prática de gestão pública orientada para resultados, no qual o planejamento se revela o instrumento técnicopolítico de transformação.

\section{Planejar é elevar a racionalidade pública a um grau superior}

Segundo Furtado (1967), cabe ser destacado o papel das estruturas de poder na análise do processo de desenvolvimento. Nesse sentido, a ação de policy makers também envolve a ação de state makers. Contudo, na atualidade, há um grande desafio de se readmitir a figura do estadista nos diversos níveis de governo (ou seja, não apenas federal, mas também estadual e municipal). A dificuldade se deve em grande medida ao quadro retratado por Dardot e Laval (2016) em que a doutrina tecnocrática ganha força e avança na sua estratégia de tutelar o poder e o espaço da política. Esse processo aprofunda contradições típicas de uma economia capitalista e, como destaca Belluzo e Galípolo (2017), o poder real cada vez menos reside objetivamente no poder representativo, mas sim nas articulações econômicas e financeiras que estão no interior da sociedade que busca se consolidar como razão de Estado. Em particular, o papel do setor financeiro influenciando crescentemente na tomada de decisão, o que inibe uma estrutura de planejamento com maior dimensão participativa e torna sua temática secundária e subordinada a temática do equilíbrio fiscal.

Esse movimento se fortalece sobre a lógica do lawfare como discutida em Martins, Martins e Valim (2019), no qual a operação do direito é usada como arma contra inimigos políticos. Isso vem extravasando a esfera do sistema judicial levando ao risco de configuração de um "Estado de exceção" como diagnosticou Valim (2017). Sob essa estratégia, técnicos do próprio serviço público passam a se ver numa "cruzada" 
acima do debate político e a ser arvorar como uma burocracia capaz de "salvar" a administração pública. Nesse sentido, penalizam orientações políticas divergentes, flexibilizam garantias constitucionais e enxergam a classe política com imbuída de uma única missão: apoiar e sancionar seus pleitos moralizadores, por se julgarem mais representantes do povo que os próprios representantes eleitos (ironicamente, como se fossem "eleitos por concurso").

Essa estrutura de poder busca induzir ao consenso forçado de que só há uma alternativa, ou melhor, uma única que fosse "responsável" independente de muitas vezes provocar severos impactos socioeconômicos negativos. A emenda que instituiu o "teto de gastos" é um grande exemplo disso. Apesar de promover o recuo das proteções sociais e um cenário de semiestagnação econômica, descumpri-la agora atenta contra a Constituição e leva a crime de responsabilidade, sustando qualquer possibilidade de divergência nos modelos de gestão. Portanto, aprofunda uma tendência punitivista sobre o que deveria ser um debate político aberto de teorias da administração pública e política econômica.

Em contraponto a esse movimento, cabe reconhecer como as sociedades nacionais realizam um processo de "destruição criativa" de seus anteparos morais, recriando-os de acordo com a maneira como se reorganiza as estruturas de mercados e as estruturas de poder ao longo da história. Um exemplo seria a legitimação social do liberalismo econômico como subproduto do projeto nacional anglo-saxão em sua fase avançada, e a recorrente contestação disso por movimentos contra-hegemônicos igualmente impulsionados por projetos nacionais rivais. A escolha de adoção ou não dos valores do liberalismo econômico ou sua antítese não é uma escolha baseada em racionalidade pura e sim confrontada a uma avaliação das necessidades históricas e objetivos estratégicos, como destaca Celso Furtado (1978a).

Nesse sentido, o planejamento bem estruturado e pactuado socialmente permite elevar o grau de racionalidade pública ao renunciar ao componente moralizador descontextualizado do sentido de um projeto nacional. Celso Furtado ofereceu diversas contribuições nesse campo por se filiar ao ideário do "Nacional-Desenvolvimentismo" (vide FURTADO, 1985). Isso porque abre a possibilidade de um capitalismo nacional organizado e com temporalidade estratégica, no qual o Estado assume uma tarefa histórica de liderança num processo socioeconômico de transformação estrutural positiva. 


\section{Planejar é a capacidade de ampliar o campo da decisão política}

Apesar de ser algo fundamental, Celso Furtado compreendia que não bastava elevar o grau de racionalidade pública. Como um dos grandes formuladores da "Teoria do Subdesenvolvimento" (vide FURTADO, 1961), entendia o desafio político de enfrentar a produção histórica singular do atraso enquanto malformação societária na periferia do sistema capitalista mundial. Como sintetizaram Cepeda e Pinto (2014) baseados na visão do mestre:

Aqui gerou-se uma civilização híbrida em sua modernização por não permitir a emergência do ethos burguês pautado no individualismo, no trabalho assalariado livre, na acumulação e inovação competitiva, em grande parte como resultado da escravidão e da produção primário-exportadora (latifundiária, ultra-especializada e reflexa), mas simultaneamente fonte de violenta produção e acumulação de capital. Ao mesmo tempo, as instituições, os valores sociais e as relações sociais ficavam travadas entre, de um lado, a preservação de interesses capitalistas não industriais e nem competitivos, e, de outro lado, pela utilização de uma racionalidade política senhorial, patrimonialista e privatista sobre o Estado.

Diante disso, Celso Furtado (1974) alertou sobre como é preciso impedir que qualquer projeto de modernização não leve a uma ilusão de desenvolvimento. Nesse sentido, o nacionalismo econômico embasando a racionalidade pública é uma condição necessária, mas insuficiente se descolado de uma preocupação essencial com o bemestar social imediato das mais amplas massas desfavorecidas da população (ou seja, que reafirmasse a condição social de exclusão dos benefícios diretos da dinâmica econômica). Sob o prisma da luta pela soberania econômica somada a homogeneização social, evidencia-se a necessidade do planejamento se tornar uma produção técnica com claro componente político que se afasta efetivamente da doutrina tecnocrática ao se aproximar de um reformismo progressista e popular.

Com o processo de redemocratização do país, essa agenda ganhou evidência ao mesmo tempo em que movimentos contestatórios a ela buscaram rechaça-la desde o início, tendo Furtado (1992) participado desse enfrentamento a essas posturas reacionárias já naquele momento. Mais recentemente, esses movimentos se aliaram a 
uma nova onda conservadora para assumir de maneira mais efetiva o controle da administração governamental. Então, os últimos anos são marcados pela execução de um projeto de recriação do Estado, conforme apontaram Dantas, Jabbour e Sobral (2016), no qual o planejamento é estigmatizado. Contudo, mesmo antes de tomar formalmente o poder com o processo de impeachment presidencial em 2016, defensores da doutrina tecnocrática já agiam "nas frestas", demarcando "domínios técnicos" e semeando valores contraditórios sobre a prática de gestão até as vias de superação estarem maduras para a ação política de conquista. Entende-se por “domínios técnicos” a forma que a cada experimentação pragmática de viés mais desenvolvimentistas que se admitisse precisava coexisitir com programas que combinavam disciplina fiscal, "realismo" cambial (e tarifário) e aperto monetário.

Portanto, adeptos da doutrina tecnocrática já se exibiam sistematicamente como os "responsáveis" a despeito de quem está formalmente no comando político e seus planos de governo. Inclusive, na aparência, muitas vezes estiveram "colaborando" no sentido de inseridos em cargos de confiança de um projeto de poder que, na essência, sempre se opuseram e garantiram que se mantivessem restrições significativas ao campo da decisão política.

Isso significa que uma cultura administrativa da "austeridade seletiva", como definida em Lodi (2019), veio sendo gestada até encontrar o contexto propício para se assumir hegemônica. Como ilustração, cabe lembrar que a política de "teto de gastos" já havia sido proposta em 2005, na ocasião apenas como discussões internas dentro governo federal. Na ocasião, Dilma Rousseff, então Ministra da Casa Civil, posicionouse contrariamente, desqualificando a proposta como "rudimentar" (CALDAS; MELLO; PEREIRA, 2005). Posteriormente, quando ela é destituída já na condição de Presidenta da República, a proposta foi encaminhada no poder executivo e aprovada no Congresso Nacional de maneira célere.

Uma lição desse processo é que o enfrentamento centrado no campo de disputa eleitoral é inócuo se não atacar a raiz da legitimidade da doutrina tecnocrática até o nível do senso comum e possibilitar a reconquista efetiva da economia pela política. Isso exige enfrentamento de um bloco histórico formando o ideário de algumas das principais escolas de administração e de gestão pública e produzindo as leis (e até as reformas constitucionais) sobre critérios que vem firmando um marco de poder acima das disputas eleitorais, ou seja, como garantidora de suposta fórmula de correção do Estado e de criminalização de quem as subverte. 
O cerne do desafio atual é que não basta só garantir unidade de atores políticos em prol de metas de realização nacional e popular, mas encaminhar, em paralelo, o debate sobre o que é responsabilidade ou, melhor dizendo, qual o conjunto de valores públicos socialmente desejados para uma classe dirigente, e quais os procedimentos de administração para o julgamento dessa classe pela história. Portanto, não basta focar no debate de fins e vontade política, e não dedicar atenção necessária ao debate de meios e qualidade da gestão. Centrar esforços em superar a estigmatização e revalorizar o papel das estruturas de planejamento permite ampliar o campo da decisão política, e, assim, dar ênfase à configuração de uma nova cultura administrativa.

\section{Planejar é o exercício discricionário para definir prioridades e temporalidades estratégicas}

Diante da necessidade de requalificar o conjunto administrativo, o grande desafio é não se assumir uma prática autoritária e de arrogância, acreditando-se respaldado por uma teoria geral ahistórica e que retirasse o conflito social do alcance de mediação pela ação política. Hoje, o exercício profissional na gestão pública, em particular quando feita por economistas de escolas teóricas convencionais, é em grande medida uma postura dogmática. Por exemplo, quando se dedica esforços para "blindar" a economia dos seus instrumentos democráticos de representação política e mobilização social.

É como se a formação acadêmica do ponto de vista de conhecimento técnico pode resvalar de forma corriqueira para um instrumentalismo cego, o que impede de se indagar a radicalidade do problema como ensina Celso Furtado $(1969,1991)^{1}$, a saber: o conhecimento profundo do que é o Brasil e suas regiões do ponto de vista do sentido da formação social, seus ciclos econômicos históricos e transições, e quais os problemas já maduros para solução política. Esse é um dos maiores legados do mestre, demonstrar a possibilidade de um esforço de teorização própria que não ocultasse a especificidade e, a partir disso, definir diretrizes e plano de ações no âmbito do planejamento.

\footnotetext{
1 Destacam-se duas grandes obras: 1) FURTADO, Celso (1969). Formação econômica da América Latina. Rio de Janeiro, Lia Editôra; e 2) FURTADO, Celso (1991). Formação Econômica do Brasil. São Paulo, Editora Nacional.
} 
No senso comum, muitas vezes se propaga a vulgar concepção teórica que o Estado "intervém" na economia e que a conceituação desta última, no sistema capitalista, é definida por "economia de mercado" e, assim, distinguindo-se de uma "economia de planejamento". Esse esquematismo, que serve para uma disciplina introdutória nos cursos de formação acadêmica, revela-se um equívoco para uma esforço de teorização mais avançado dos sistemas econômicos em que se exige uma mínima noção de Economia Política, como também se revela um falso dilema na prática da gestão. Afinal, esse esquematismo impede a compreensão do próprio capitalismo em uma perspectiva histórica, algo criado junto à formação dos Estados nacionais e para sua consolidação. Da mesma forma, isso impede a compreensão da centralidade que possui as dimensões territorial e institucional para o sucesso de um processo de desenvolvimento.

Em diversas obras, Celso Furtado foi um grande questionador da teoria econômica convencional ao indagar que era preciso compreender o desenvolvimento como um sistema integrado de decisões e estruturas, e destacar o papel das ações indutoras e buscar a transformação estrutural positiva. Isso significa modificar o curso dos mercados prefigurados e recriar novas estruturas alinhadas a uma agenda de modernização. O mercado se deixado como um conjunto de automatismos baseados em "leis" econômicas (os supostos "bons" fundamentos pela teoria econômica convencional) seria tão somente um conjunto de decisões induzidas por uma racionalidade abstrata que resvala para o dogmatismo sem qualquer validade histórica.

Influenciado por Gunnar Myrdal, Albert Hirschman e François Perroux, o mestre sempre lembrou de que toda racionalidade pública não se sustenta meramente por axiomas lógico-dedutivos. Ao contrário, está associada ao processo social em que se evidencia uma estrutura de poder dotada de uma capacidade de coordenar a partir da tomada de uma decisão indutora e a força de propagação em uma cadeia de decisões. Isso garante que não haja a sobreposição da lógica de projetos individuais sobre a perspectiva de planejamento a ponto de romper inércias. Isso ele chama de ação disruptiva, ou seja, uma decisão autônoma que gera uma cadeia de decisões sob uma lógica integradora e cumulativa, ou seja, com reações no mesmo sentido da ação inicial reforçando e concentrando seu poder de direção. Logo que não se condiciona somente pela estrutura socioeconômica existente, sob a premissa de sustentar pontos de equilíbrio, mas que se volta para sua superação do ponto de vista inovativo. 
Ao chamar atenção para o papel das estruturas de poder e ação disruptiva, Celso Furtado (1977) também reivindica o retorno do conceito de excedente social para o centro do debate sobre desenvolvimento. A partir disso, o mestre recoloca o papel do Estado como uma unidade dominante na economia, logo capaz de internalizar centros de decisão em seu território. Nesse sentido, um agente fundamental para economia, que deve ter o desenvolvimento institucional e integração territorial suficiente para se revelar capaz de se antecipar as decisões particulares e reorientá-las a fim de compatibilizar por uma programação e sistema de incentivos.

Ao invés da retórica do ajuste fiscal como um fim em si mesmo e reformas prómercado, a ênfase passa a ser o destravamento dessa capacidade de macrocoordenação pública de decisões, e realizar as mediações necessárias entre os diversos grupos sociais para criar um consenso sobre o papel de sua ação indutora para o desenvolvimento. Nesses termos que o planejamento se revela o exercício por excelência de discriminação e escolha de prioridades.

Uma economia forte não se resume a mercantilização generalizada e multiplicação de oportunidades de negócios. Planejar é a capacidade da gestão pública distinguir e hierarquizar, não podendo tomar de antemão qualquer interesse particular como representante do interesse público. O interesse particular contribui ao interesse público não por um conjunto de boas intenções declaradas de geração de emprego e renda, mas pela capacidade do Estado coordenar decisões e oferecer um plano de desenvolvimento que defina uma temporalidade estratégica que o incorpore.

Essa temporalidade é um aspecto decisivo, dado que amplia as possibilidades de rentabilidade para os diversos tomadores de decisão privados e permite acionar setores líderes, buscando aproveitar todo o potencial de encadeamentos e adensamentos produtivos. Isso significa que decisões que não se justificariam individualmente pelas condições pré-existentes, passam a ser confirmadas pelo horizonte ampliado de decisões em cadeia que emerge em cenários prospectivos. Então, não se trata de impedir que qualquer desequilíbrio micro ou macroeconômico surja, mas que ao surgir não aborte a condução desse processo organizado. Afinal, muitas vezes o resultado positivo não é aparente de imediato, precisando um conjunto de ações sequenciais programadas ser completado para vingar e suas condições de realização estarem amadurecidas. 


\section{Conclusão: o planejamento possui competências inescapáveis}

A importância de Celso Furtado transcende os limites de um campo do saber diante de sua preocupação de lidar com o processo histórico em sua totalidade. Não obstante o valor da interdisciplinaridade, importante demarcar seu ponto de partida: as Ciências Econômicas. Nesse sentido, cabe enfatizar que o mestre é um dos grandes pensadores econômicos, e, desse lugar, demonstra que os economistas brasileiros não estão fadados ao "economicismo", crítica corriqueira de colegas de outras áreas afins nas Ciências Sociais. Ao contrário, demonstra que o papel de um economista brasileiro pode estar a serviço de uma radicalidade sintetizada na temática do planejamento: indagar sobre o sentido de um projeto nacional próximo às aspirações de um reformismo progressista e popular, a fim de construir um consenso sobre o papel do Estado e sua ação indutora para o desenvolvimento.

De fato, a questão nacional é essencial e unificadora das diversas lutas políticas ao requalificar uma agenda de modernização para que não redunde numa ilusão de desenvolvimento. Não existe possibilidade de sustentar o enfrentamento do combate à miséria, à desigualdade e o avanço em direitos humanos e sociais num país rendido a uma estratégia entreguista no contexto internacional. O cerne das lutas políticas ainda é consolidar nossa independência, baseada na unidade territorial de uma nação com claro projeto soberano. Caso contrário, corre-se o risco de seguir "ideias fora do lugar", fruto de movimentos internacionalistas que não lidam com o exame de nossas especificidades. Em particular, a influência de intelectuais europeus e norte-americanos que, apesar de bem intencionados em sua solidariedade as lutas do campo progressista, são incapazes de tratar com centralidade nossa condição periférica. Antes que extremamente desiguais, somos primeiro produtos de uma lógica de periferização que resiste e se reatualiza.

A luta pela superação do estatuto periférico na ordem global só pode ser explorada em todo seu potencial se estiver identificada com uma nova cultura administrativa pública capaz de requalificar as competências do planejamento e, assim, ampliar a relação entre o Estado e a sociedade no seio da gestão estratégica. Portanto, ao contrário de encarar o Estado como o problema e se pautar pela negação de sua tarefa histórica num processo de desenvolvimento. Essa agenda poderá ser a base de uma renovada classe dirigente que, através do processo de planejamento baseado numa 
maior dimensão participativa, habilite-se a comandar o processo histórico isolando qualquer aspiração tecnocrática.

\section{Fontes}

FURTADO, Celso (1961). Desenvolvimento e subdesenvolvimento. Rio de Janeiro: Fundo de Cultura. . (1967). Teoria e Politica do Desenvolvimento Econômico. São Paulo: Editora Nacional. . (1969). Formação econômica da América Latina. Rio de Janeiro, Lia Editôra. (1974). O Mito do Desenvolvimento Econômico. Rio de Janeiro: Paz e Terra. . (1977). Prefácio a nova economia política. Rio de Janeiro, Paz e Terra. (1978a). A hegemonia dos Estados Unidos e o subdesenvolvimento da América Latina. Rio de Janeiro: Civilização Brasileira. (1985). A fantasia organizada. Rio de Janeiro: Paz e Terra. . (1991). Formação Econômica do Brasil. São Paulo, Editora Nacional. (1992). A construção interrompida. Rio de Janeiro: Paz e Terra.

\section{Referências bibliográficas}

BELLUZZO, Luiz Gonzaga; GALÍPOLO, Gabriel (2017). Manda quem pode, obedece quem tem juízo. São Paulo: Contracorrente.

CALDAS, Suely; MELLO, Patrícia Campos; PEREIRA, Renée (2005). Plano de ajuste de longo prazo é rudimentar e não está em debate. Estado de São Paulo, Economia, p. B4, nov.

D’AGUIAR, Rosa Freire (org.) (2019). Celso Furtado: diários intermitentes 1937-2002. Rio de Janeiro: Companhia das Letras.

DANTAS, Alexis; JABBOUR, Elias; SOBRAL, Bruno (2016). "A recriação conservadora do Estado: impasses no reformismo progressista e popular com golpe de 2016". Revista da ANPGE, v.12, n.19: 5-38. Disponível em: < http://ojs.ufgd.edu.br/index.php/anpege/article/download/6372/3323 >.

DARDOT, Pierre; LAVAL, Christian (2016). A nova razão do mundo. São Paulo: Boitempo.

LODI, Ricardo (2019). Desigualdade e Tributação na Era da Austeridade Seletiva. Rio de Janeiro: Lumen Juris.

MARTINS, Cristiano Zanin; MARTINS, Valeska Teixeira Zanin;VALIM, Rafael (2019). Lawfare: uma introdução. São Paulo: Contracorrente.

VALIM, Rafael (2017). Estado de exceção: a forma jurídica do neoliberalismo. São Paulo: Contracorrente.

Artigo recebido em 28 de julho de 2020.

Aprovado em 06 de novembro de 2020.

DOI: 10.12957/intellectus.2020.54039 